\title{
Imigração haitiana no Estado de Santa Catarina: Fases do fluxo e contradições da inserção laboral.
}

\author{
Luís Felipe Aires Magalhães ${ }^{1}$ \\ Rosana Baeninger ${ }^{2}$
}

\begin{abstract}
RESUMO
A emigração haitiana não é um processo novo (CASTOR, 1978; COTINGUIBA, 2014): iniciada ainda no final do século XIX, quando se dirige especialmente a Cuba e República Dominicana, ela se orienta, já na segunda metade do século XX, a países como Estados Unidos, Canadá e França. Estes processos históricos de emigração internacional possuem particularidades, não apenas quanto às razões da migração como também no que se refere aos fluxos e suas principais características. No entanto, a emigração haitiana passa, atualmente, por uma transformação: a crise capitalista pós-2008 (MAGALHÃES e BAENINGER, 2014) repercutiu diretamente nos níveis de emprego, salário e poupança, em países constituídos como destinos tradicionais da emigração haitiana (França e Estados Unidos, especialmente), o que trouxe duas consequências importantes. A primeira, o fortalecimento do sentimento e da prática xenófobos, em razão das restrições no mercado de trabalho e a apropriação disto por setores conservadores, intensificando com isto a seletividade migratória nestes países (MAGALHÃES e BAENINGER, 2014). A segunda, também decorrente destas restrições no mercado de trabalho, foi a diminuição do nível de remessas de migrantes, o que provocou rápido contágio da crise em países dependentes de remessas, como o Haiti (CEPAL, 2009). Diante destas dificuldades (econômicas, políticas e sociais), a migração haitiana teve de reorientar-se, ou seja, encontrar novos países de destinos (FERNANDES, MILESI e FARIAS, 2011). Neste momento, o Brasil passava por um ciclo expansivo em sua economia, implementando medidas anticíclicas de promoção do consumo e de construção de obras públicas - inclusive para a realização de grandes eventos internacionais, como a Copa do Mundo de Futebol de 2014 e os Jogos Olímpicos de 2016. De igual modo, o Brasil estava presente também no Haiti, seja militarmente, coordenando a Missão da ONU para Estabilização da Paz no país (LUCE, 2011; PATARRA, 2012), seja economicamente, através de um sem-número de empreiteiras operando inicialmente a construção de estradas e portos e, após o Terremoto de Janeiro de 2010, a reconstrução do país (SEGUY, 2014). Estes fatores inseriram o Brasil no rol dos destinos da emigração haitiana, ainda no final do ano de 2010 (MAGALHÃES e BAENINGER, 2014). O entendimento da presença haitiana no Brasil exige um conjunto de esforços teóricos e metodológicos. No que concerne aos esforços teóricos, há de se considerar que a emigração haitiana é um processo histórico de longa duração, que envolve desde o final do século XIX um conjunto de países, sob diversas condições sociais e políticas vigentes no Haiti (CASTOR, 1978). Explicações como a de uma migração originada por conta exclusiva do terremoto devem ser, portanto, questionadas (SEGUY, 2014; COTINGUIBA, 2014). De igual modo, a presença haitiana no Brasil requer, metodologicamente, utilização de outras fontes de dados (FERNANDES, 2014), visto que o último Censo Demográfico brasileiro deu-se antes da chegada massiva destes imigrantes. Registros como o do Ministério das Relações Exteriores (MRE), do Ministério do Trabalho e Emprego (MTE) além das informações, qualitativas e quantitativas, de pesquisas nacionais existentes sobre o tema devem ser, portanto, utilizados.
\end{abstract}

\footnotetext{
${ }^{1}$ Doutorando no Departamento de Demografia IFCH - UNICAMP, pesquisador no Observatório das Migrações em São Paulo e pesquisador no Observatório das Migrações no Estado de Santa Catarina (CAPES/UDESC).

${ }^{2}$ Professora no Departamento de Demografia IFCH - UNICAMP, pesquisadora no Núcleo de Estudos de População (NEPO)/UNICAMP e coordenadora do Observatório das Migrações em São Paulo (FAPESP / CNPq-NEPO / UNICAMP, nº. 2014/04850).
} 
Este trabalho objetiva apresentar um panorama da presença haitiana no Brasil, baseado nas exigências teóricas e metodológicas acima descritas, conferindo especial atenção à imigração haitiana no Estado de Santa Catarina e sua inserção laboral. Duas hipóteses sublinham este trabalho: inicialmente, a hipótese de que a presença haitiana no Brasil guardaria relações com a própria presença brasileira no Haiti, através da disseminação de informações imprecisas sobre as condições de vida e de trabalho no Brasil; nossa segunda hipótese é a de que a imigração haitiana em Santa Catarina não se fixa nas cidades de destino, pelo contrário, se dispersa pelo território catarinense de modo que podemos falar de uma mobilidade interna desta migração internacional, mobilidade esta essencialmente laboral. A metodologia utilizada contempla a realização de pesquisa de natureza qualitativa nas cidades de Balneário Camboriú e de Chapecó. Apresentamos como resultado uma periodização da presença haitiana em Santa Catarina e um perfil social e demográfico deste fluxo de imigrantes no Estado. 


\section{Introdução}

O Haiti expressa, como poucos países do mundo, o sucesso do projeto colonial vigente na América Latina e como ele pode significar a tragédia de um país, isto é, o desenvolvimento de seu subdesenvolvimento: de colônia mais próspera do século XVII e XVIII, se transformou em país mais pobre da América atualmente (PIERRE-CHARLES, 1990, JAMES, 2010). A revolta escrava no país, pelo controle nacional e também pelos preceitos de liberdade, igualdade e fraternidade, ocasionou um dos episódios mais originais da história contemporânea: a Independência Negra do Haiti, a $1^{\text {o }}$ de Janeiro de 1804 (JAMES, 2010). Conquistada duramente, a Independência Haitiana deparou-se, rapidamente, com os entraves colocados pelas potências imperialista de sua época, que condenaram e condenam ainda o país à uma situação de completa marginalidade na divisão internacional do trabalho (JAMES, 2010). A "lição" do imperialismo começara com a emissão de sucessivas tropas do exército de Napoleão com a finalidade exclusiva de dizimar lideranças políticas nacionais, atear fogo às plantações e destruir todas as estruturas produtivas do país (JAMES, 2010; MANN, 2012). Outro elemento particularmente importante é que, mesmo com a Independência conquistada, a presença militar, primeiro francesa, depois norteamericana e atualmente inclusive brasileira continua perpassando o território haitiano, sob relativa anuência internacional (LUCE, 2007), dado que orquestrada pela ONU, mas com repercussões nada desprezíveis sobre sua sociedade e estruturas políticas (CASTOR, 2008). Este país, formado por intensa tradição migrante (CASTOR, 1978; COTINGUIBA, 2014; HANDERSON, 2015), tem desde 2010 orientado fluxos migratórios também ao Brasil (FERNANDES, MILESI e FARIAS, 2011; PATARRA, 2012; COTINGUIBA, 2014; MAGALHÃES, 2014; HANDERSON, 2015). Neste artigo, buscaremos analisar a formação destes fluxos para a cidade de Balneário Camboriú (Estado de Santa Catarina), apontar alguns primeiros resultados da pesquisa sobre a inserção laboral dos imigrantes e suas contradições e apresentar alguns conceitos que julgamos possam ser elucidativos sobre o processo migratório e o envio e utilização de remessas de migrantes.

\section{A Migração Sul - Norte}


A emigração haitiana não é um fenômeno novo. Desde os anos 1960, ela tem crescido sistematicamente, em especial para países centrais no sistema capitalista, como Estados Unidos e França. Estes fluxos migratórios específicos, situados dentro de um esquema migratório Sul - Norte, possuem um conteúdo histórico que não pode ser desprezado e lança luzes sobre a própria presença haitiana no Brasil: tanto Estados Unidos como França são países que historicamente exercem controle econômico, político e inclusive militar sobre o Haiti. Enquanto a presença francesa no país inscreve-se no marco da economia colonial e fragmenta-se com a Independência, a ocupação militar norte-americana no Haiti tem início em 1915, e embora tenha sido destituída em 1934, institucionalizou sua presença no sistema econômico e político do país (CASTOR, 1971).

Como em outros países do mundo, a presença estrangeira demonstrou ser capaz de criar e condicionar relações entre os dois países que envolvem, inclusive, fluxos migratórios do país invadido ao país invasor. Deslocam-se nestes fluxos os chamados "migrantes coloniais", que são grupos sociais que migram em fluxo no sentido inverso ao da ocupação externa. A segunda metade do século XX apresentou claros exemplos desta modalidade migratória: caribenhos nos Estados Unidos, argelinos na França, asiáticos na Inglaterra, peruanos e equatorianos na Espanha etc. Analisar a migração do Haiti aos Estados Unidos neste sentido é um passo essencial para se pensar a migração de haitianos ao Brasil, com suas características específicas.

Os fatores de expulsão populacional no Haiti foram germinados historicamente e possuem como principal expressão as precárias condições de vida no país, o que faz da emigração internacional uma forma tradicional de busca de melhoria social e econômica (DURAND, 2014).

Atualmente, 1.134.000 haitianos residem fora do país, isto é, 11,05\% da população do país (MPI, 2013). Historicamente, os Estados Unidos são o destino preferencial dos emigrantes haitianos. De 1960 até 2010, o total de emigrantes haitianos nos Estados Unidos passou de 5.000 para 606.000 , chegando, atualmente, a representar $1,5 \%$ de toda a população imigrante norte-americana (MPI, 2014), conforme o Gráfico 1:

Gráfico 1 - Imigrantes haitianos residentes nos Estados Unidos (1960 - 2010): 


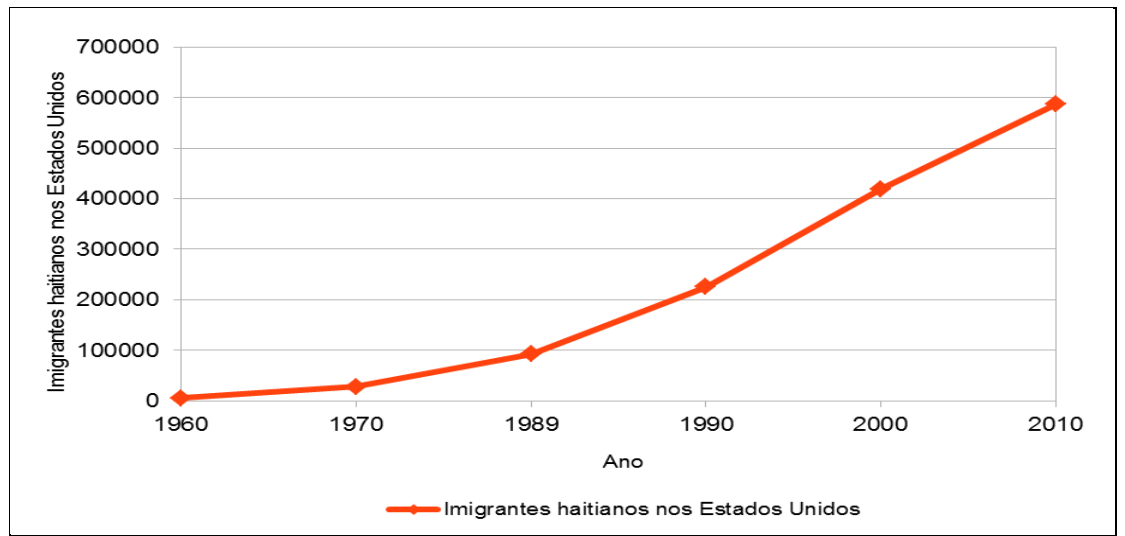

Fonte: MPI, 2014.

Mas a situação de que saem estes haitianos, produto histórico que é, precisa ser melhor compreendida. Diante da Independência no país, o sistema capitalista mundial reage ao levante de libertação no Haiti de modo a desaconselhar o exemplo aos demais povos da periferia, condenando o país ao embargo econômico e ao isolamento comercial. Não devemos entender com isto que o Haiti foi excluído do sistema capitalista mundial. Pelo contrário, ele aprofundou sua vinculação a ele, de forma ainda mais subordinada. (CASTOR, 2008; JAMES, 2010).

Militar e economicamente, os Estados Unidos se tornam presença fixa no Haiti no século $\mathrm{XX}$, dominando diretamente as escassas estruturas produtivas do país e influenciando a política nacional de acordo com o interesse de suas empresas. As últimas décadas do século XX aprimoraram esta dinâmica, intensificando a polarização de classe no país e agravando as condições sociais de tal modo que o consenso nacional se torna secundário frente à necessidade de uma solução armada aos conflitos sociais (CASTOR, 2008): sucessivos golpes e deposições se tornam a face mais visível de um país dramaticamente desigual. A presença militar externa requeria ser renovada, justificada, para a manutenção da estrutura social e econômica no país. Neste contexto que a ONU interviu no país, com o exército brasileiro à frente, através da Minustah. A partir deste momento, e por meio de outros fatores que descreveremos a seguir, dá-se uma diversificação nos destinos migratórios do povo haitiano, e emerge um esquema migratório Sul - Sul.

\section{Desenvolvimento: Haitianos no Estado de Santa Catarina}


As informações que se seguem são referentes à pesquisa de campo de natureza qualitativa realizada em Balneário Camboriú, cidade litorânea do Estado de Santa Catarina, localizada a $81 \mathrm{~km}$ da capital estadual (Florianópolis) e com população residente estimada em 124.557 pessoas (FIBGE, 2015). Estima-se que residam em torno de 500 imigrantes haitianos na cidade (ASHAN, 2014). A pesquisa de campo iniciou-se com entrevistas realizadas no ambiente de trabalho e seguiu com a realização delas na Associação dos Haitianos de Balneário Camboriú (ASHABC). Estas entrevistas foram realizadas entre os meses de Março e Junho de 2014. Ao todo, foram entrevistados 31 trabalhadores haitianos, todos eles trabalhadores do setor de supermercados e construção civil, exceto Jennie ${ }^{3}$, que trabalha como diarista. Na sequência desta primeira saída a campo, tivemos a oportunidade ainda de aplicarmos questionário que vem sendo utilizado nacionalmente na pesquisa Haitianos no Brasil: Perfil e trajetórias em algumas cidades brasileiras, sob a coordenação do professor Dr. Sidney Antônio da Silva (INCT Brasil Plural) em conjunto com o Observatório das Migrações em São Paulo (NEPO-UNICAMP/FAPESP-CNPq) e com o Observatório das Migrações em Santa Catarina (UDESC-CNPq).

Do grupo de 31 haitianos entrevistados, 24 deixaram o país através de um voo entre sua capital, Porto Príncipe, e a cidade de Quito, no Equador. Neste sentido, o fluxo específico de haitianos em Balneário Camboriú se assemelha ao fluxo geral de haitianos no Brasil. Como observa Patarra (2012):

\begin{abstract}
o processo de entrada desses imigrantes em território brasileiro é semelhante na quase totalidade dos casos. A viagem começa em Porto Príncipe ou na República Dominicana, e por via aérea chegam a Lima, Peru, ou em Quito, no Equador, países que não exigiam visto de entrada para os haitianos. Destas duas cidades partem por via terrestre em uma viagem que pode se estender por mais de um mês, ao longo do percurso eles vão alternando trechos percorridos em ônibus e barcos" (PATARRA, 2012, ps. 13-14).
\end{abstract}

A viagem longa a que se refere Patarra (2012) é até a fronteira do Brasil com o Peru, nos Estados do Acre e do Amazonas. Estes imigrantes que chegaram à América do Sul desembarcando em Quito, entraram no Brasil deslocando-se de ônibus desta última cidade até a fronteira do Peru com o Estado do Acre. Apenas três imigrantes entraram pelo estado do Amazonas, três imigrantes entraram no Brasil através da fronteira do Paraná com a Argentina, na cidade de Barracão, e outros cinco imigrantes chegaram diretamente de avião na cidade de São Paulo.

\footnotetext{
${ }^{3}$ Nome fictício. Todas as identidades dos haitianos entrevistados serão preservadas utilizando nomes fictícios. Todas as demais informações são fidedignas.
} 
A maioria dos imigrantes haitianos residentes em Balneário Camboriú chegou ao Brasil em situação de indocumentados, sem os documentos necessários à fixação de um estrangeiro no país. A Tabela 1 apresenta as informações sobre a condição de chegada, se documentada ou indocumentada, dos imigrantes haitianos entrevistados:

\section{Tabela 1 - Condição de chegada dos imigrantes haitianos entrevistados}

\begin{tabular}{l|c}
\hline Condição de chegada & Total \\
\hline Documentada & 7 \\
\hline Indocumentada & 24 \\
\hline Total & 31 \\
\hline
\end{tabular}

Fonte: Pesquisa de campo (INCT Brasil Plural/Observatório das Migrações em São Paulo/Observatório das Migrações em Santa Catarina), julho de 2014.

Dos sete haitianos que chegaram ao Brasil documentados, cinco tiveram como ponto de chegada a cidade de São Paulo. Clarkson, de 33 anos de idade, é um deles: chegou ao Brasil em 12 de Novembro de 2012, com visto de permanência por 5 anos, obtido na Embaixada Brasileira em Santo Domingo. Como dito, a posse do visto o fez não ter de se submeter à longa viagem entre Equador ou Lima e o Estado do Acre. Pelo contrário, viajou diretamente de Santo Domingo a Navegantes, com escalas na Cidade do Panamá e em São Paulo. De Navegantes, dirigiu-se imediatamente a cidade de Balneário Camboriú, onde sua mulher, Ayllen, que viera antes à cidade, o esperava. Um dia após chegar a Balneário Camboriú, Clarkson foi a Itajaí, onde há um escritório da Polícia Federal. Lá obteve a sua Cédula de Identidade Estrangeira, com validade até 2017.

Jeremie, de 32 anos de idade, é um dos 20 imigrantes que chegaram indocumentados ao país. Sua viagem foi, por consequência, mais longa e perigosa. Do Haiti, viajou de ônibus à República Dominicana, país vizinho na ilha caribenha, de onde viajou de avião até a Cidade do Panamá. Do Panamá, embarcou de avião até Quito, onde iniciou uma viagem de 6 dias de ônibus até o Acre, passando por Lima. Ficou dois meses sob péssimas condições no Acre. Quando regularizou sua situação, obtendo CPF e Cédula de Identidade de Estrangeiro, viajou a Balneário Camboriú, recrutado pela empresa Imbrasul Construtora e Incorporadora. No dia 17 de Novembro de 2011 chegou à cidade. Dois anos e dez dias depois, vieram sua esposa e seu filho. Jeremie recordou na entrevista que trabalhou intensamente em dois empregos para juntar, durante este período, $\mathrm{R} \$ 5.470$ para a compra das passagens da esposa e do filho. 
O Gráfico 2, por sua vez, nos permite analisar a estrutura etária do grupo de 31 imigrantes haitianos entrevistados.

\section{Gráfico 2 - Estrutura etária dos haitianos entrevistados.}

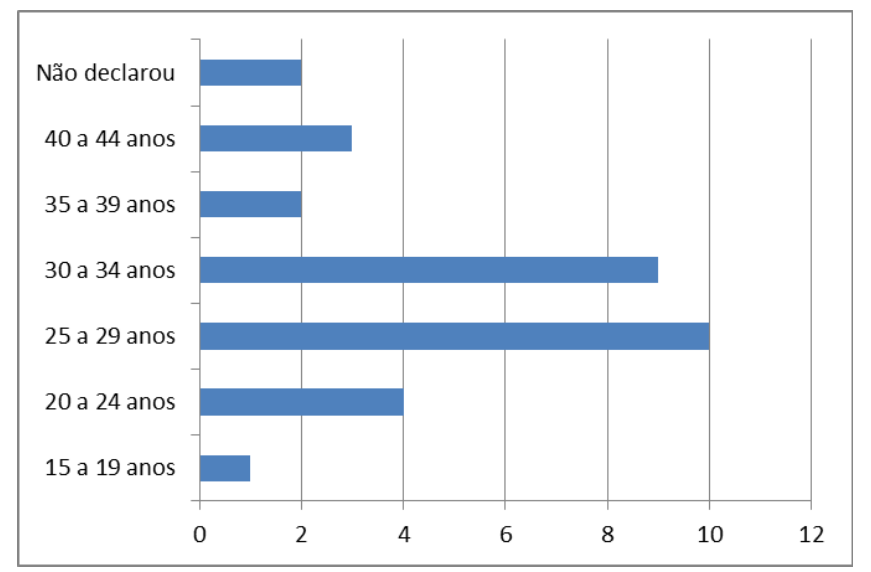

Fonte: Pesquisa de campo (INCT Brasil Plural/Observatório das Migrações em São Paulo/Observatório das Migrações em Santa Catarina), julho de 2014.

O mais jovem haitiano entrevistado é Antoine, de 22 anos. O mais velho é Yves, de 44 anos. Ambos chegaram indocumentados ao país. A concentração da idade dos entrevistados nos grupos etários mais produtivos revela que estamos diante de um grupo que chegou a Balneário Camboriú principalmente para trabalhar.

Vimos, até o momento, que a presença haitiana em Balneário Camboriú chegou ao Brasil principalmente de forma indocumentada, e possui estrutura etária caracteriza pela concentração de imigrantes em idade produtiva. Estes dois elementos são de fundamental importância para entendermos a inserção laboral destes imigrantes.

Mas como chegam a Balneário Camboriú os imigrantes haitianos? Que caminhos os levam da fronteira do Acre ou Amazonas com o Peru, ou da cidade de São Paulo (para aqueles que chegaram ao Brasil de forma documentada)? A resposta a esta questão nos aproxima um pouco mais dos objetivos deste artigo e do entendimento da inserção laboral dos imigrantes haitianos na cidade e suas contradições. Nossas pesquisas indicam que esta pergunta possui diferentes respostas, dependendo do momento do fluxo a que estamos nos referindo.

Atualmente, isto é, para os fluxos migratórios atuais, a resposta reside na atuação das redes sociais: os amigos e parentes que já migraram dão referências positivas do lugar àqueles 
que ficaram, os incentivando a migrar e construindo uma rede de relações sociais e laborais na qual o migrante se inserirá. Previamente, já se tem garantias de emprego, hospedagem e ajuda inicial. Todos estes elementos são facilmente observados entre os haitianos em Balneário Camboriú: a rede social, fortalecida pela criação da Associação dos Haitianos em Balneário Camboriú no dia 05 de Março de 2013, é o que verdadeiramente dá sequência hoje ao fluxo, especialmente através do desejo e iniciativa de trazer à Balneário Camboriú os parentes que ficaram no Haiti. Todos os haitianos entrevistados declararam que deixaram família no Haiti. E isto aponta para outro elemento importante deste fluxo e central para a economia do Haiti, que veremos adiante: as remessas de migrantes.

Outro aspecto desta etapa atual do fluxo de imigrantes haitianos é a proporção maior de crianças e mulheres, especialmente no ônibus que têm chegado do Acre nos últimos meses. Este proporção maior indica utilização da possibilidade do visto de reunificação familiar, que permite a vinda dos familiares residentes no Haiti ao Brasil.

As redes sociais, materializadas hoje no espaço de ajuda mútua representado pela Associação dos Haitianos da cidade, são um elemento fundamental da atual conjuntura migratória internacional e de como Balneário Camboriú se insere nela. Todavia, no tempo germinal do fluxo migratório, as redes sociais são mais produto que causa destes fluxos, de modo que outro fator incidiu inicialmente na orientação da trajetória migratória dos haitianos rumo a Balneário Camboriú. As respostas aos questionários aplicados indicam haver uma forte atuação de três empresas catarinenses no recrutamento e contratação de força de trabalho, ainda no Acre. Estas empresas foram até as cidades fronteiriças do Acre buscar a força de trabalho haitiana. Estas empresas são a Multilog, a Ambiental e a Imbrasul Construtora e Incorporadora.

A Multilog é uma empresa de logística em comércio exterior, sediada no município de Itajaí, vizinho de Balneário Camboriú. Seu principal produto é a armazenagem de bens, seu transporte para exportação, especialmente no Mercosul, e outros serviços conexos.

Os imigrantes haitianos recrutados no Acre pela Multilog desempenham, essencialmente, a função de estivadores, estoquistas e de serviços gerais. 
A Ambiental é uma empresa de execução de obras e de realização de serviços de limpeza urbana em nove cidades do Estado de Santa Catarina: Balneário Camboriú, Camboriú, Itajaí, Itapema, Indaial, Jaraguá do Sul, Joinville, São Francisco do Sul e São José. Além da coleta e transporte de lixo, a Ambiental faz ainda tratamento de resíduos sólidos e operações de saneamento básico, e emprega diretamente mais de 1.800 trabalhadores.

Os imigrantes haitianos recrutados no Acre pela Ambiental desempenham, essencialmente, as funções de garis e de serviços gerais.

A Imbrasul Construtora e Incorporadora é uma empresa sediada no município de Navegantes, distante $34 \mathrm{~km}$ de Balneário Camboriú. Constrói edifícios de alto padrão na região, especialmente na praia de Gravatá.

Os imigrantes haitianos recrutados no Acre pela Imbrasul desempenham, essencialmente, as funções de pedreiro, auxiliar de pedreiro, servente e serviços gerais.

Em síntese: os primeiros haitianos em Balneário Camboriú trabalhavam como garis no município e no porto de Itajaí. Alguns haviam sido recrutados no Acre para trabalhar na construção civil em Navegantes, mas os atrativos em Balneário Camboriú (especialmente a maior oferta de emprego e acesso a serviços e a proximidade com os haitianos residentes em Balneário Camboriú) rapidamente os atraíram. Realizavam, portanto, tarefas mais intensas no uso da força física, menos qualificadas. Foi apenas posteriormente que os trabalhadores haitianos dirigiram-se ao trabalho nos outros setores, principalmente o de supermercados. Nos supermercados, desempenham funções relacionadas ao trabalho no setor de cozinha (como cozinheiros dos próprios colegas de trabalho, que fazem suas refeições nos supermercados), estoque e reposição de produtos, horti-fruti e açougue. Não há registro de trabalhadores haitianos em funções de gerência ou mesmo de caixa de supermercados na cidade de Balneário Camboriú.

Importante, ainda, para avaliarmos a conjuntura desta inserção laboral dos imigrantes haitianos é perceber que a cidade de Balneário Camboriú não corresponde ao destino final de muitos imigrantes, mas pelo contrário, constitui-se como etapa de uma trajetória migratória que se destina, sobretudo, à Mesorregião Oeste do Estado. 
Regularmente, são realizados recrutamentos de empresas frigoríferas do Oeste de Santa Catarina nas cidades do Vale do Itajaí, especialmente Balneário Camboriú. Pudemos participar de uma das reuniões de recrutamento, no que percebemos a utilização da promessa do alojamento gratuito (na realidade, há desconto da folha salarial). Esta promessa torna-se tanto mais tentadora quanto mais caros são os aluguéis pagos por estes imigrantes em Balneário Camboriú. Até nosso último levantamento, foram 150 imigrantes haitianos residentes em Balneário Camboriú que deixaram a cidade com destino a Chapecó. Segundo relato da própria associação dos haitianos de Chapecó, a cidade é, atualmente, o município de maior população imigrante haitiana no Estado de Santa Catarina.

Ademais, a análise da data de chegada ao Brasil dos haitianos entrevistados sugere que o fluxo ainda está em expansão, como indica a Tabela 2.

Tabela 2 - Ano de chegada dos imigrantes haitianos entrevistados.

\begin{tabular}{|l|c|}
\hline Ano de chegada à cidade & Total \\
\hline 2011 & 2 \\
\hline 2012 & 4 \\
\hline 2013 & 15 \\
\hline 2014 & 7 \\
\hline Não respondeu & 3 \\
\hline Total & $\mathbf{3 1}$ \\
\hline
\end{tabular}

Fonte: Pesquisa de campo (INCT Brasil Plural/Observatório das Migrações em São Paulo/Observatório das Migrações em Santa Catarina), julho de 2014.

Quando perguntados sobre o desejo de voltar ao Haiti, os entrevistados tiveram de fazer um balanço principalmente entre a saudade dos familiares que ficaram, as condições de vida e de trabalho em Balneário Camboriú, além de suas perspectivas, e as duras condições de vida reinantes no Haiti. O resultado desta mediação não foi uniforme, conforme se pode observar na Tabela 3.

Tabela 3 - Desejo de retorno ao Haiti.

\begin{tabular}{|l|c|}
\hline Retorno ao Haiti & Total \\
\hline Deseja voltar & 12 \\
\hline Não deseja voltar & 13 \\
\hline Deseja apenas para visita & 3 \\
\hline Deseja ir para outro país & 2 \\
\hline Total & $\mathbf{3 1}$ \\
\hline
\end{tabular}

Fonte: Pesquisa de campo (INCT Brasil Plural/Observatório das Migrações em São Paulo/Observatório das Migrações em Santa Catarina), julho de 2014. 
Com estas informações preliminares sobre a imigração haitiana em Balneário Camboriú, podemos inserir agora o tema das remessas de migrantes para o melhor entendimento deste fluxo. A Tabela 4 apresenta informações sobre envio de remessas aos familiares que permanecem no Haiti.

Tabela 4 - Envio de remessas aos familiares que permanecem no Haiti.

\begin{tabular}{|l|c|}
\hline Remessas de migrantes & Total \\
\hline Envia & 25 \\
\hline Não envia & 3 \\
\hline Não respondeu & 3 \\
\hline Total & $\mathbf{3 1}$ \\
\hline
\end{tabular}

Fonte: Pesquisa de campo (INCT Brasil Plural/Observatório das Migrações em São Paulo/Observatório das Migrações em Santa Catarina), julho de 2014.

É predominante a realização de remessas, mesmo sob as duras condições do mercado de trabalho em que atuam os haitianos e os gastos elevados com aluguel. Clarkson, por exemplo, envia no dia 10 de cada mês remessas no valor de $\mathrm{R} \$ 1.000,00$ para seus pais, que ficaram no Haiti. Para tal, possui dois empregos, e sua esposa também trabalha.

As entrevistas revelaram, ainda, que as remessas não chegam a ultrapassar $\mathrm{R} \$ 1.500,00$, e que o valor monetário mais comum é o de envio de até $\mathrm{R} \$ 500,00$.

Tabela 5 - Valor das remessas dos imigrantes haitianos entrevistados em Balneário Camboriú - SC.

\begin{tabular}{|l|c|}
\hline Valor & Total \\
\hline Até $\mathrm{R} \$ 500,00$ por envio & 8 \\
\hline De $\mathrm{R} \$ 500,1$ a $\mathrm{R} \$ 1.000,00$ por envio & 3 \\
\hline De $\mathrm{R} \$ 1.001$ a $\mathrm{R} \$ 1.500,00$ por envio & 2 \\
\hline Mais de $\mathrm{R} \$ 1.500,00$ por envio & 0 \\
\hline Não envia remessas & 1 \\
\hline Total & $\mathbf{1 4}$ \\
\hline
\end{tabular}

Fonte: Pesquisa de campo (INCT Brasil Plural/Observatório das Migrações em São Paulo/Observatório das Migrações em Santa Catarina), julho de 2014.

Os haitianos, ao chegar ao Brasil, têm recebido Cadastro de Pessoa Física (CPF) e Carteira de Trabalho. Os dois documentos são de fundamental importância para a abertura de contas bancárias e o envio financeiro das remessas.

Tabela 6 - Forma de envio das remessas pelos imigrantes haitianos entrevistados em Balneário Camboriú - SC. 


\begin{tabular}{l|c}
\hline Forma de utilização das remessas pela família & Total \\
\hline Consumo familiar & 12 \\
\hline Moradia de dependentes & 3 \\
\hline Investimento econômico & 0 \\
\hline Investimento em estudo de dependentes & 11 \\
\hline Total & $\mathbf{2 6}$ \\
\hline
\end{tabular}

Fonte: Pesquisa de campo (INCT Brasil Plural/Observatório das Migrações em São Paulo/Observatório das Migrações em Santa Catarina), julho de 2014.

A falta de regularidade no envio das remessas, isto é, sua natureza instável, também é um elemento presente no cotidiano dos imigrantes haitianos residentes em Balneário Camboriú e no de suas famílias no Haiti.

Tabela 7 - Regularidade das remessas dos imigrantes haitianos entrevistados em Balneário Camboriú - SC.

\begin{tabular}{|l|c|}
\hline Há regularidade no envio de remessas? & Total \\
\hline Sim & 2 \\
\hline Não & 11 \\
\hline Total & 13 \\
\hline
\end{tabular}

Fonte: Pesquisa de campo (INCT Brasil Plural/Observatório das Migrações em São Paulo/Observatório das Migrações em Santa Catarina), julho de 2014.

Gerard, que apenas recentemente encontrou um emprego (estava desemprego há dois meses, desde que o negócio em que trabalhava fechara as portas), recebe $\mathrm{R} \$ 900$ líquidos em seu trabalho de operador de estoque em uma empresa da cidade. Disto, entrega mensalmente $\mathrm{R} \$ 400,00$ para o aluguel de seu quarto sem janela, de aproximadamente $15 \mathrm{~m}^{2}$. O que sobra deve ser mensalmente sacrificado para que seja possível, tal como ele declarou, enviar remessas de até $\mathrm{R} \$ 500,00$ a sua família no Haiti. Ao fazer este sacrifício, Gerard sabe o quanto este valor é importante para a subsistência de sua família. Por isto envia os recursos. Gerard e todos os imigrantes haitianos entrevistados que responderam ao questionário sobre remessas afirmaram enviar remessas com a finalidade de sustentar a sua família. Não houve nenhuma resposta que afirmasse a finalidade de compra de imóvel, de automóvel ou abertura de negócio, conforme se pode visualizar na Tabela 8: 
Tabela 8 - Finalidade do envio de remessas ao Haiti.

\begin{tabular}{l|c}
\hline Finalidade do envio das remessas ao país de origem & Total \\
\hline Sustento da família & 13 \\
\hline Compra de imóvel & 1 \\
\hline Compra de automóvel & 0 \\
\hline Abertura de negócio & 1 \\
\hline Total & $\mathbf{1 5}$ \\
\hline
\end{tabular}

Fonte: Pesquisa de campo (INCT Brasil Plural/Observatório das Migrações em São Paulo/Observatório das Migrações em Santa Catarina), julho de 2014.

A finalidade com que as remessas são enviadas nem sempre corresponde, no entanto, à forma com que elas são utilizadas pelos familiares residentes no país de origem. Neste quesito, interpelamos os imigrantes haitianos residentes em Balneário Camboriú permitindo a eles que dessem respostas múltiplas.

Tabela 9 - Forma de utilização das remessas pelos familiares no país de origem.

\begin{tabular}{|l|c|}
\hline Forma de utilização das remessas pela família & Total \\
\hline Consumo familiar & 12 \\
\hline Moradia de dependentes & 3 \\
\hline Investimento econômico & 0 \\
\hline Investimento em estudo de dependentes & 11 \\
\hline Total & $\mathbf{2 6}$ \\
\hline
\end{tabular}

Fonte: Pesquisa de campo (INCT Brasil Plural/Observatório das Migrações em São Paulo/Observatório das Migrações em Santa Catarina), julho de 2014.

Através destes dados, percebe-se que as remessas são utilizadas pelos familiares essencialmente para consumo e para o financiamento dos estudos dos dependentes dos migrantes. Aproximamo-nos, com isto, do ponto central deste artigo: os conceitos de "dependência de remessas" e "síndrome emigratória” no Haiti.

\section{Conclusões: dependência de remessas e síndrome emigratória no Haiti.}

Os dados sobre remessas de migrantes entre os imigrantes haitianos entrevistados, destacam que estes recursos são destinados e utilizados efetivamente para o consumo e a subsistência 
das famílias no país de origem. No âmbito da teoria crítica sobre as remessas de migrantes ${ }^{4}$, esta utilização não pode ser desprezada ou ignorada: trata-se de famílias que desenvolvem relações de dependência com estas remessas.

A dependência de remessas é um conceito que expressa a necessidade crescente que algumas famílias envolvidas no processo migratório têm dos recursos enviados pelos familiares ao país de origem. Esta dependência faz menção direta não tanto ao nível dos recursos enviados, mas mais à forma com que estes recursos são utilizados. Neste sentido, as famílias serão dependentes à medida que tais recursos sejam predominantemente utilizados para o consumo, a subsistência da família, o pagamento dos gastos correntes com alimentação e educação, por exemplo. Como vimos, este é o caso do grupo imigrante analisado neste artigo: as remessas são enviadas exclusivamente para o sustento da família, e utilizadas, por sua vez, apenas para financiamento de consumo e de educação (e em menor medida, para gastos com moradia dos familiares). Não há qualquer menção, seja na finalidade do envio seja propriamente na utilização das remessas, a um investimento econômico, produtivo ou financeiro, destes recursos. A dualidade entre consumo e investimento é particularmente importante no estudo das remessas por que ela não se refere apenas às opções e escolhas tomadas pela família, mas também, e principalmente, às suas necessidades mais urgentes, as quais são condicionadas por sua posição na estrutura econômica e social do país de origem. Em outras palavras, a forma de utilização das remessas é uma expressão da estratificação socioeconômica no Haiti. É justamente nos domicílios mais pobres onde as remessas serão utilizadas prioritariamente para consumo. Segundo Binford (2002),

os investimentos das remessas - ou os efeitos indiretos de seu desembolso provém a base para condições de trabalho humanas e um nível de remuneração suficiente para sustentar um modo de vida digno. Numerosos domicílios individuais, e a maioria dos domicílios em inúmeras comunidades rurais ricas em recursos, têm usado o dinheiro das remessas para ascender economicamente, ao menos por certo tempo. Sem embargo, um número abrumador de domicílios e de comunidades não o tem logrado, e um número cada vez maior tem ficado preso à 'síndrome da emigração', na qual a emigração internacional provoca maior emigração, fornecendo a base para que um nível de vida mais alto somente possa manter-se graças a um fluxo constante de remessas (BINFORD, 2002, p. 146).

As remessas funcionariam, então, como um mecanismo de expansão do consumo das famílias receptoras, desencadeando uma relação de dependência, por parte destas famílias,

\footnotetext{
${ }^{4}$ Para conhecimento dos principais autores e contornos teóricos desta interpretação, ver MAGALHÃES, 2013.
} 
em relação a estes recursos, ou seja, constituindo a chamada "dependência de remessas". O acréscimo no nível do consumo, por seu turno, amplia as necessidades materiais destas famílias. A ausência de estruturas produtivas inclusivas no país faz com que esta expansão no nível de consumo ou mesmo a sua manutenção seja possível apenas com o afluxo de novas remessas, o que concretamente tende a significar a emergência de novos fluxos migratórios, isto é, a emigração de outros familiares que permaneciam no país de origem. A literatura crítica sobre remessas conceitua esta situação de "síndrome emigratória". Derivada de uma condição de dependência de remessas, ela expressa a situação limite de centralidade das migrações internacionais para a manutenção material de inúmeras famílias, e a elevação das remessas a um status de elemento da dinâmica migratória - dado que condiciona novos fluxos ao exterior.

Jenevieve tem 24 anos. Seus pais vivem em Miami, nos Estados Unidos. Migraram quando Jenevieve ainda era uma criança. Jenevieve tem um filho pequeno, que permanece com o restante de sua família no Haiti. Trata-se de uma família cujos membros vivem em três países diferentes (Estados Unidos, Brasil e Haiti). A tradição de migração aos Estados Unidos foi rompida por Jenevieve, que migrou ao Brasil em um momento marcado, como vimos, por dificuldades na entrada e no emprego de imigrantes nos Estados Unidos, o que repercute sobre o nível das remessas enviadas. A migração ao Brasil, dentro deste contexto, é mais que um projeto individual: trata-se de uma estratégia familiar de manutenção do nível de consumo, dificultado com a intensificação da crise social e econômica pósterremoto. Uma estratégia que expressa, a ausência de garantias e perspectivas de reprodução social no Haiti, e a síndrome emigratória provocada pela busca destas garantias e perspectivas em outros países.

O conceito de síndrome emigratória é particularmente útil para a análise histórica do caso haitiano, pois confere conteúdo teórico à expressão “povo migrante”. Neste artigo, tivemos por objetivo caracterizar a imigração haitiana na cidade de Balneário Camboriú, por meio de informações derivadas de questionário aplicado a um grupo de 25 imigrantes residentes na cidade, e mediar estas informações com dois conceitos que nos parecem úteis para a análise do caso haitiano: a dependência de remessas e a síndrome emigratória. Estes dois conceitos nos indicam que é essencial para o estudo das remessas de migrantes o entendimento da estrutura social e econômica do país de origem, de modo a avaliarmos a 
forma de utilização das remessas e suas consequências. Em outras palavras, tão importante quanto o volume destes recursos é sob que condições e para que finalidade eles são utilizados. Saímos dos Balanços de Pagamentos e chegamos, assim, à família, que se torna então dimensão importante para o estudo de remessas. Mas também as condições e a finalidade se alteram entre as famílias, de modo que é essencial as situarmos na estrutura de classe do país. A posição das famílias nestas estruturas condiciona a forma de utilização dos recursos. Isto, por seu turno, valida a introdução e o resgate histórico que elaboramos neste estudo (pois estas estruturas formaram-se em condições concretas que vigoram ainda no país) ao passo que também concede importante contribuição analítica à perspectiva histórico-estrutural.

\section{Referências Bibliográficas}

APPADURAI, Arjan. A Vida Social das Coisas: As mercadorias sob uma perspectiva cultural. Niterói: EdUFF, 2008.

ASHAN, Associação dos Haitianos de Navegantes. Primeiro Seminário da ASHAN sobre Haitianos em Navegantes. Navegantes, 03 de Agosto de 2014.

BARRICARTE, J. J. S. Socioeconomía de las migraciones en un mundo globalizado. Madrid: Biblioteca Nueva, 2010. 352.

BINFORD, Leigh. Remesas y Subdesarrollo en México. Revista Relaciones, Benemérita Universidad Autónoma de Puebla, nº 90, v. XXIII, Primavera 2002. Pg. 116 - 158.

CASTOR, Suzy. A Transição Haitiana: Entre os perigos e a esperança. In: SADER, Emir (Org.). Cadernos de Pensamento Crítico Latino-Americano, v.2. São Paulo: Expressão Popular/CLACSO, 2008. 144p.

CASTOR, Suzy. La ocupación norteamericana de Haití y sus consecuencias (1915-1934). México D.F: Siglo XXI Editores, 1971. 232p.

CEPAL (2009a) La Actual Crisis Financiera Internacional Y Sus Efectos En América Latina Y El Caribe. Disponível em: http://www.cepal.org/publicaciones/xml/0/35390/2009-25-

Thecurrentinternationalfinancialcrisis_ESPANOL-WEB.PDF. Acesso em Fevereiro de 2015.

CODAS, Gustavo. O Direito do Paraguai à Soberania: A questão da energia hidrelétrica. São Paulo: Expressão Popular, 2008.

COTINGUIBA, Geraldo Castro. Imigração haitiana para o Brasil: a relação entre trabalho e processos migratórios. Dissertação (Mestrado em História e Estudo Culturais) - Fundação Universidade Federal de Rondônia/UNIR/RO, 2014.

COVARRUBIAS, Humberto Márquez. Desarrollo y Migración: Una lectura desde la Economia Política. Revista Migración y Desarrollo, $\mathrm{n}^{\circ}$ 14, primeiro semestre de 2010. Pg. 59-87.

FERNANDES, Duval (Coord.). Projeto "Estudos sobre a Migração Haitiana ao Brasil e Diálogo Bilateral”. Belo Horizonte: TEM/IOM-OIM/PUC Minas/GEDEP, 2014. 
FERNANDES, Duval; MILESI, Rosita; FARIAS, Andressa. Do Haiti para o Brasil: o novo fluxo migratório. In: Cadernos de Debates Refúgio, Migrações e Cidadania, v. 6, nº 6 (2011). Brasília: Instituto Migrações e Direitos Humanos. P. $73-98$.

Fundação Instituto Brasileiro de Geografia e Estatística. Banco de Dados Países, 2014. Disponível em: http://www.ibge.gov.br/paisesat/.

GROSFOGUEL, Ramón. Migrantes Coloniales Caribeños em los Centros Metropolitanos del SistemaMundo. Los casos de Estados Unidos, Francia, los Países Bajos y el Reino Unido. In: Documentos CIDOB, v. 13 - série migraciones, Junho de 2007. Pp. 01-51.

Haity y la Salida Migratória, Jorge Durand. Periódico LaJornada. Disponível em http://www.jornada.unam.mx/2010/01/31/opinion/010a1pol. Acesso em Fevereiro de 2014.

HANDERSON, Joseph. Diaspora. As dinâmicas da mobilidade haitiana no Brasil, no Suriname e na Guiana Francesa. Tese de Doutorado. Programa de Pós-Graduação em Antropologia Social, Universidade Federal do Rio de Janeiro (UFRJ)/Museu Nacional, 2015.

JAMES, Ceryl. Os Jacobinos Negros: Toussaint L'Ouverture e a revolução de São Domingos. São Paulo: Boitempo Editorial, 2010. 400p.

LUCE, Mathias S. A Superexploração da Força de Trabalho no Brasil. In: Revista da Sociedade Brasileira de Economia Poítica, São Paulo, nº 32, p. 119 - 141, junho - 2012.

LUCE, Mathias S. A Teoria do SubImperialismo em Ruy Mauro Marini: Contradições do capitalismo dependente e a questão do padrão de reprodução do capital. A história de uma categoria. Tese de Doutoramento. Universidade Federal do Rio Grande do Sul. Porto Alegre, 2011.

LUCE, Mathias S. O Subimperialismo brasileiro revisitado: a política de integração regional do governo Lula (2003 - 2007). Dissertação de Mestrado. Universidade Federal do Rio Grande do Sul. Porto Alegre, 2007.

MAGALHÃES, Luís Felipe Aires. O Haiti é Aqui: Análise das informações preliminares sobre os imigrantes haitianos em Santa Catarina - Brasil. In: VI Congresso da Associação Latino-Americana de População, Lima - Peru, de 12 a 15 de Agosto de 2014. Pôster.

MAGALHÃES, Luís Felipe Aires. Migração Internacional e Dependência na Divisão Internacional do Trabalho: um estudo da região sul de Santa Catarina. Dissertação de Mestrado. Universidade Estadual de Campinas, Unicamp. Campinas, 2013.

MARINI, Ruy Mauro. Dialética da Dependência. Petrópolis: Vozes, 2000. 295p.

MARINI, Ruy Mauro. Subdesenvolvimento e Revolução.2ª ed. Florianópolis: Insular, 2012. 272p.

METZNER, Tobias. La migración haitiana hacia Brasil: estúdio en el país de origem. In: OIM. La Migración Haitiana Hacia Brasil: Características, oportunidades y desafios. Cuadernos Migratórios $\mathrm{N}^{\circ} 6$. Buenos Aires: OIM, 2014. Ps. 15-33.

MPI. Migration Policy Institute.

PATARRA, Neide Lopes. O Brasil: País de imigração? In: Revista E-Metropolis, nº 09, ano 3, junho de 2012. Pg. $01-18$.

PIERRE-CHARLES, Gérard. Haiti (1930-1975): A Crise Ininterrupta. In: CASANOVA, Pablo González (Org.). América Latina: História de meio século, v. 3. Brasília: Editora UnB, 1990. 296p.

SALES, Teresa. Migrações de Fronteira entre o Brasil e os Países do Mercosul. In: Revista Brasileira de Estudos Populacionais (REBEP), Campinas, v. 13(1), 1996. Pg. 87 - 98.

SASSEN, Saskia. The Mobility of Labor And Capital: A study in international investiment and labor flow. Cambridge: Cambridge University Press, 1988. 
SEGUY, Franck. A catástrofe de janeiro de 2010, a "Internacional Comunitária" e a recolonização do Haiti. Tese (Doutorado em Sociologia) - Universidade Estadual de Campinas, Instituto de Filosofia e Ciências Humanas. Campinas, 2014.

SINGER, Paul. Economia Política da Urbanização. 15ª ed. São Paulo: Brasiliense, 1995. 154p.

SILVA, Sidney Antônio da. "Aqui começa o Brasil”: Haitianos na Tríplice Fronteira e Manaus. In: SILVA, Sidney Antônio da (Org). Migrações na Pan-Amazônia: Fluxos, fronteiras e processos socioculturais. São Paulo: Hucitec Editora, 2010. Pp. 300 - 321. 